\title{
Editorial
}

\section{Why branding, as we know it, is about to collapse}

Image-based branding - the Disneys, the Nikes and the Starbucks - is an extreme capitalist construct, built on the alienation of humans from themselves, and is therefore ultimately doomed to fail. (I know this sounds strange coming from a proponent of branding, but be patient if you can. I have an alternative and will get to it soon. Let me first explain what I'm talking about.)

Under capitalism, humans must suppress their innate, non-monetary needs - for self-reflection, self-expression, time with loved ones, a natural environment, and so on - in order to earn money. Every activity is shaped (perverted) by the pressure to earn. Young children are trained to pass tests rather than simply enjoy learning. College students seek high-paying vocations rather than following their interests. Couples work primarily on their jobs and secondly on their relationships. And older people, who used to look forward to retirement, find they simply cannot afford it and work until they literally cannot any more. (And all of us are living in the city, or close by, because we have to get to work.)

So we live in a world where people have, essentially, exchanged their humanity for currency, just as Marx explained it. We've put a price tag on ourselves, and on all the elements of our lives, and in doing so we are part of an interlocking system that holds each of its members in place. In this system, humans go to the marketplace not only to purchase what they need, but to find what they have given up - to pay for its return in an alienated form. We may have lost our right to nature, but we sure as hell can buy the Timberland boots that enable us to explore it (if the opportunity should ever arise, that is). We may not have enough time for ourselves, but damn if we can't head into Starbucks and buy ourselves a cup of it, in the form of a 'grande' French roast. And maybe we can't invest hours and hours getting to know our kids, but we most assuredly can take them to Disney.

Image branding was made to order for this system where priceless humanity has been priced, tagged and packaged for quick, just-in-time distribution, in handy, conveniently sized chunks. It is the attempt to exploit humans' need to recapture what they lost, gave up, or had taken from them because of the triumph of capitalism. Unlike classical branding, which functioned simply as a seal of trust between buyer and seller (and affirmed the basic human need for security), image branding is all about turning people into products and products into people.

So the lure of image branding, its promise if you will - over and above the promise of any one particular branded entity - is to deliver substitute human interaction that is almost 
as good as the real thing. Not only that, but image-brand gratification has none of the downside of genuine human activity - no messy demands that interfere with your ability to participate in the marketplace. It takes a lot of time to train for a marathon, but only a few seconds to buy a Nike running outfit, right? And when you wear one you see yourself as having achieved something, and others see you that way too.

You see, your relationship with yourself is the beginning of the image-brand promise, because the way you perceive yourself shapes the way you relate to others, and how they see you in return. I may not be wealthy and stylish, but if I buy a Mercedes and wear Prada, I feel that way, and others treat me accordingly. They are part of the same social-cultural system, and can read the signs and symbols.

Image brands interlock with the capitalist system to promise us that we can have our cake and eat it too. We can make the money we need to survive in a world run by money, and feel like we're living meaningful, achievement-laden lives at the same time - even if we're spending all our time working to pay for things. Not only that, say image brands, but the more we buy, and the more we crave, the more fully alive we are.

Yet here is where the system falls apart: it's a fake, and people know it. In fact, they buy particular brands specifically to create identities that do not really exist. They therefore know, inside, that they are fakers, and that the brand is fake as well. This reminds me of something the great Rabbi Nachman of Breslov once said: that the evil impulse is like a trickster who runs around asking 'What do you suppose I have in my hand?'. When you pay the fee (or sell your soul), you find out that there is - nothing.

Since the image-brand system is built on fakery, it is vulnerable to any point in the illusion where the fakery cannot be sustained in a consistent way. That is why image brands tend to emphasise slick packaging: it is easy to fool ourselves when we see advertisements, jewel cases, car exteriors and fabric. But image brands fall apart on the one dimension that cannot truly be bought, ironically the one dimension that would lend the most credence to the deception - customer interaction with the brand's service representatives. I can will myself to believe that the fragile world created by the brand is real and perfect, that the brand can give me friendship and respect, until the very first moment I deal with a human representative of the brand who acts in a way that is inconsistent with the illusion.

If the brand's human service representatives can fake it well enough, the brand can be sustained for a time. But even this is doomed to fail over the long term, because - although they say they understand the 'human factor' or whatever - most companies today have zero comprehension of how critical people are to their brands. Instead, the focus is on whatever products and services they sell, which in the end are, of course, doomed to be generic. So they don't know how to treat people, they don't know how to pay people, and they don't know how to create a culture where a consistent brand image can be sustained.

Lost and drifting, confused and irritated by the intrusion of messy humanity into their perfect worlds, image-branders find themselves unable 
to use their brands to sustain a competitive advantage. They have only the vaguest understanding of what it is that they really sell, and only the most tenuous connection to the people who, in the end, sustain their companies, both as consumers and as producers of the brand.

Now, I believe that there is an alternative possibility here: to acknowledge the 'doom spiral' of image branding and shift to another, lifeaffirming paradigm instead. Brands can and should go back to serving as genuine marks of value, to serving as an objective intermediary between consumer and consumed, even to emphasising the fact that a product is just a product, and nothing more. In so doing, they would once again become names people trust to help them live their lives more fully. But it will take a sea change in thinking to achieve this: marketers will have to give up the pursuit of image and instead focus on creating and delivering products and services that provide real honest value with no promise of anything over and above functionality itself. In that world, a toaster is just a toaster; a car is just a car; and a musical band is just a musical band. The difference between brands and generics, then, becomes the difference between companies you can trust and those you can't.

Of course, trust branding wouldn't undo the damage that the endless pursuit of money does to the human psyche. But it certainly would stop adding to it. And it might, just might, return to the discipline of branding what little integrity it has left.

(C) 2004 Dannielle Blumenthal 